\title{
In Vitro Assessment of the Enzymatic Degradation of Several Starch Based Biomaterials
}

\author{
Helena S. Azevedo, ${ }^{\dagger}, \neq \neq$ Francisco M. Gama, ${ }^{\S}$ and Rui L. Reis ${ }^{\dagger, \ddagger}$ \\ 3B's Research Group-Biomaterials, Biodegradables and Biomimetics, University of Minho, Campus de \\ Gualtar, 4710-057 Braga, Portugal, Department of Polymer Engineering, University of Minho, Campus de \\ Azurem, 4800-058 Guimarães, Portugal, and Centro de Engenharia Biologica, IBQF, Largo do Paço, \\ Universidade do Minho, P-4710-057 Braga, Portugal
}

Received May 9, 2003; Revised Manuscript Received July 14, 2003

\begin{abstract}
The susceptibility of starch-based biomaterials to enzymatic degradation by amylolytic enzymes (glucoamylase and $\alpha$-amylase) was investigated by means of incubating the materials with a buffer solution, containing enzymes at different concentrations and combinations, at $37^{\circ} \mathrm{C}$ for 6 weeks. Two polymeric blends of corn starch with poly(ethylene-vinyl alcohol) copolymer and poly( $\epsilon$-caprolactone), designated by SEVA-C and SPCL, respectively, were studied. The material degradation was characterized by gravimetry measurements, tensile mechanical testing, scanning electron microscopy (SEM), and Fourrier transform infrared-attenuated total reflectance (FTIR-ATR). The degradation liquors were analyzed for determination of reducing sugars, as a result of enzyme activity, and high performance anion exchange chromatography with pulsed amperometric detection (HPAEC-PAD) was used to identify the degradation products. All of the analysis performed showed that starch polymeric blends are susceptible to enzymatic degradation, as detected by increased weight loss and reducing sugars in solution. $\alpha$-Amylase caused significant changes on the overall mechanical properties of the materials, with a decrease of about $65 \%$ and $58 \%$ being observed in the moduli for SEVA-C and SPCL, respectively, when compared with the control (samples incubated in buffer only). SEM analysis detected the presence of fractures and pores at the material's surface as a result of starch degradation by amylolytic enzymes. FTIR spectra confirmed a decrease on the band corresponding to glycosidic linkage $(-\mathrm{C}-\mathrm{O}-\mathrm{C}-$ ) of starch after incubation of the materials with $\alpha$-amylase. In contrast, the incubation of the polymers in buffer only, did not cause significant changes on the material's properties and morphology. Comparing the two materials, SEVA-C exhibited a higher degradability, which is related to the physicochemical structure of the materials and also to the fact that the starch concentration is higher in SEVA-C. The identification of the degradation products by HPAEC-PAD revealed that glucose was the major product of the enzymatic degradation of starch-based polymers. $\alpha$-Amylase, as expected, is the key enzyme involved in the starch degradation, contributing to major changes on the physicochemical properties of the materials. Nevertheless, it was also found that starch-based polymers can also be degraded by other amylolytic enzymes but in a smaller extent.
\end{abstract}

\section{Introduction}

The ability of a material to be resorbed over time is an important property in many biomedical applications. This feature may be necessary to achieve a certain biological function, e.g., to support the gradual ingrowth and ultimately complete the replacement of a regeneration matrix by normal tissue, as well as to avoid the risk of complications that may be associated with the long-term presence of a foreign material. ${ }^{1,2}$ Many biodegradable polymers have been developed for a variety of applications such as in orthopaedic surgery, drug delivery, and tissue engineering. ${ }^{1-6}$ These materials have been designed to degrade over controllable periods of time originating degradation products with low toxicity.

* To whom correspondence should be addressed. E-mail address: hazevedo@dep.uminho.pt. Phone: +351-253604781. Fax: +351-253604492.

†3's Research Group, University of Minho.

Department of Polymer Engineering, University of Minho.

$\S$ Centro de Engenharia Biológica, IBQF, Universidade do Minho.
The degradation of some biomaterials involves nonenzymatic hydrolysis which is largely nonregulated. ${ }^{1}$ The degradation rate of these materials is normally controlled by manipulation of the physicochemical properties of the materials (crystallinity, molecular weight, chemical composition, hydrophilicity, and surface area). An alternative approach is to let the degradation proceed along the coordinate of the healing process, rather than time, by making the material sensitive to the feedback provided by the cells involved in the healing response, ${ }^{3}$ as cells enzymatically degrade the extracellular matrix around them. In this context, it may be useful to take advantage of materials that are degraded in response to cellular activities. For instance, the use of synthetic biomaterials that degrade in response to specific cellularly derived proteases has been investigated. ${ }^{7}$ In this way, the tissues will determine the rate of resorption of the material, rather than the calendar.

Another approach that has been investigated is the inclusion of enzymatic recognition sites into polymer backbones, 
Table 1. Description of the Enzymatic Degradation Tests

\begin{tabular}{llc}
\multicolumn{1}{c}{ condition } & \multicolumn{1}{c}{ description ${ }^{a}$} & $\begin{array}{c}\text { enzyme activity } \\
(\mathrm{U} / \mathrm{mL})\end{array}$ \\
\hline PBS & buffer only $($ control $)$ & 0 \\
Gluc1 & glucoamylase $(0.6 \mathrm{mg} / \mathrm{mL})$ & 10.5 \\
Gluc2 & glucoamylase $(2.4 \mathrm{mg} / \mathrm{mL})$ & 41.8 \\
Amyl1 & $\alpha$-amylase $(0.6 \mathrm{mg} / \mathrm{mL})$ & 1819 \\
Amyl2 & $\alpha$-amylase $(2.4 \mathrm{mg} / \mathrm{mL})$ & 7275 \\
Gluc+Amyl & glucoamylase $+\alpha$-amylase $(0.6 \mathrm{mg} / \mathrm{mL}+0.6 \mathrm{mg} / \mathrm{mL})$ & $10.5 ; 1819$ \\
Gluc+Amyl+Pull & glucoamylase $+\alpha$-amylase+pullulanase $(0.6 \mathrm{mg} / \mathrm{mL}+0.6 \mathrm{mg} /$ & $10.5 ; 1819 ; 6$ \\
& $\mathrm{~mL}+0.6 \mathrm{mg} / \mathrm{mL})$ & \\
\hline
\end{tabular}

${ }^{a}$ To study the effect of different amylolytic enzymes on the degradation of starch-based materials, it was used the same concentration for each enzyme, in terms of protein content (measured by the Bradford assay). ${ }^{b}$ The activity of each enzyme was determined by incubating the proper enzyme dilution with soluble potato starch $(1 \%, \mathrm{w} / \mathrm{v})$ in PBS solution $(\mathrm{pH} 7.4)$ at $37^{\circ} \mathrm{C}$ for $10 \mathrm{~min}$. The amount of reducing sugars produced was measured

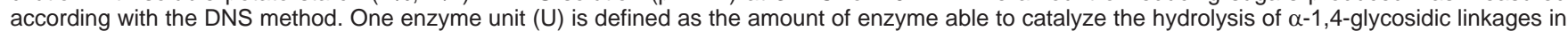
starch with the release of $1 \mu \mathrm{mol}$ of reducing sugar, measured as glucose, per minute.

such as amino acids, to enzymatically modulate the material degradation. ${ }^{8-9}$

Materials to be used in some applications, such as hardtissue replacement, must compromise adequate mechanical properties and controlled biodegradability. It may be difficult to achieve the desired combination of degradation and physical properties for a single material. In this context, the development of new enzyme immobilization methodologies, for strategically incorporate specific enzymes on the materials, to accelerate the degradation rate, in the case of shortterm applications or to degrade the polymeric matrix containing a bioactive agent and then trigger the release of the product, may constitute a rather useful approach. For that, it is necessary to understand the effects of specific enzymes on the degradation kinetics of the different materials in order to design biomaterials exhibiting controlled degradation rate.

Starch-based polymers have been studied as potential materials to be used in several biomedical applications. ${ }^{10-19}$ They were found to be biocompatible and non-cytotoxic ${ }^{12,13}$ and have shown great processing versatility being proposed for applications such as drug delivery carrier systems, ${ }^{14-16}$ hydrogels and partially degradable bone cements, ${ }^{14,16}$ materials for bone replacement/fixation or fillers for bone defects, ${ }^{17}$ and porous structures to be used as scaffolds in tissue engineering of bone and cartilage. ${ }^{18,19}$

The main enzymes involved in starch hydrolysis are $\alpha$-amylases, $\beta$-amylases, glucoamylases, $\alpha$-glucosidases, and other debranching enzymes. ${ }^{20}$ Glucoamylase releases $\alpha$-D-glucose from the nonreducing end of starch chains and is present in human small intestine. ${ }^{21} \alpha$-Amylase is an endo-specific enzyme which catalyses the hydrolysis of $\alpha-1,4$-glycosidic linkages of starch to maltose and dextrins, reducing the molecular size of starch. ${ }^{22}$ It was also shown that $\alpha$-amylase was even able to degrade chemically modified starch. ${ }^{22}$ It is also important to notice that $\alpha$-amylase can be found not only in saliva but also in human blood. ${ }^{23}$

The present study investigates the effect of different enzymes ( $\alpha$-amylase and glucoamylase) that may be involved in the degradation of starch-based biomaterials, with the perspective of developing strategies to control and tailor their degradation rate for distinct biomedical applications.

\section{Materials and Methods}

Materials and Processing. The materials studied in this work were polymeric blends of corn starch with (i) poly(ethylene-vinyl alcohol) copolymer (SEVA-C, 50/50 wt \%) and (ii) poly ( $\epsilon$-caprolactone) (SPCL, 30/70 wt \%). These commercial materials were supplied by Novamont (Novara, Italy) in granule form and were processed by conventional injection moulding, under optimized conditions, in a Klockner-Ferromatik Desma FM20 machine to produce compact disks $(\varnothing=1 \mathrm{~cm})$ and ASTM dumb-bell tensile test samples (cross section $2 \times 4 \mathrm{~mm}^{2}$ ), as described in previous studies. ${ }^{10}$ Further information on the biomaterials properties may be found elsewhere. ${ }^{10,24}$

Enzymatic Degradation Tests. The enzymatic degradation tests were carried out by using a single enzyme or by combining the different modes of action of the enzymes to study the effect on the overall hydrolysis of starch. Pullulanase is a debranching enzyme, acting on $\alpha$-1,6-glycosidic linkages of amylopectin to produce linear oligosaccharide chains containing $\alpha-1,4$-glycosidic linkages. It was used to evaluate if its activity could contribute for the increase of the degradation rate of starch polymeric blends.

The source of the studied enzymes was the following: $\alpha$-amylase (EC 3.2.1.1) was from Bacillus amyloliquefaciens, glucoamylase (EC 3.2.1.3) was from Aspergillus niger, and pullulanase (EC 3.2.1.41) was from Bacillus licheniformis. These enzymes were gently supplied by Genencor International, Inc. (Rochester, NY).

Preweighed samples were incubated in a ratio 1:10 with phosphate buffered saline (PBS) solution (0.01 M, pH 7.4) containing different enzyme concentrations at $37{ }^{\circ} \mathrm{C}$ with constant shaking at $60 \mathrm{rpm}$ for 6 weeks. Sodium azide $(0.02 \%)$ was added to the buffer solution to prevent microbial growth. The various enzyme concentrations and combinations used in this study are presented in Table 1. A control was also performed by incubating the samples in buffer alone. At the end of the degradation period, the samples were placed between two filter papers, to remove excess of liquid, and immediately weighed for determination of water uptake. Then they were washed with distilled water and allowed to dry in an oven at $60{ }^{\circ} \mathrm{C}$ for $72 \mathrm{~h}$. After cooling in a desiccator, the samples were weighed, and the weight was 
taken to determine the weight loss. SPCL samples were maintained inside the desiccator until constant weight because of low melting temperature of PCL. Degradation solutions were frozen for later analysis of enzyme activity and identification of degradation products by liquid chromatography (please see below). Enzyme activity was determined by measuring the concentration of reducing sugars liberated into the solution using the dinitrosalicyclic acid (DNS) method. ${ }^{25}$ Four replicates were performed for each condition.

Physical and Chemical Characterization. Morphological Studies-Scanning Electron Microscopy (SEM). The surface morphology of starch-based materials before and after enzymatic degradation was observed in a Leica Cambridge S360 scanning electron microscope. The samples were previously sputter-coated with gold in an Ion Sputter JEOL JFC 1100 equipment. Microphotographs at the surface were taken at various magnifications.

Tensile Testing. Tensile tests were carried out to evaluate the changes in the mechanical properties after the enzymatic treatments. For that, similar enzymatic experiments were performed in tensile specimens. These samples were processed as described for the disks. They are dumb-bell tensile test samples with a cross section of $2 \times 4 \mathrm{~mm}^{2}$ according with ASTM standards. After these treatments, the samples were washed with distilled water and maintained in a controlled environment $\left(23{ }^{\circ} \mathrm{C}, 55 \% \mathrm{RH}\right)$ until mechanical testing. The samples were tensile tested in an Instron 4505 Universal Testing machine. An Instron 3630 resistive extensometer with $10 \mathrm{~mm}$ of gauge length was used. The tests were carried out using a cross-head speed of $5 \mathrm{~mm} / \mathrm{min}(8.3$ $\times 10^{-5} \mathrm{~m} / \mathrm{s}$ ) until $1.5 \%$ strain and then increased to $50 \mathrm{~mm} /$ $\min \left(8.3 \times 10^{-4} \mathrm{~m} / \mathrm{s}\right)$ until fracture. Five samples were tested for each condition. These tests allowed the determination of the secant modulus at $1 \%$ strain $\left(E_{1 \%}\right)$, the ultimate tensile strength (UTS) and the strain at break $\left(\epsilon_{\mathrm{r}}\right)$.

Analysis of Chemical Changes by Fourrier Transform Infrared-Attenuated Total Reflectance (FTIR-ATR) Spectroscopy. The changes in the chemical composition on the surface of starch-based polymers, before and after enzymatic degradation, were analyzed by FTIR-ATR. IR spectra of each component of the blend were performed to identify the characteristic bands. Corn starch in powder (Sigma) was analyzed by $\mathrm{KBr}$ pellet. The spectra were recorded by at least 32 scans with a resolution of $2 \mathrm{~cm}^{-1}$ in a FTIR spectrophotometer (Perkin-Elmer 1600 Series). All of the other samples were analyzed by using a single reflection ATR system (MKII Golden Gate, Specac) with a diamond crystal (angle of incidence $=45^{\circ}$; active sampling area 0.8 $\times 0.8 \mathrm{~mm}$; depth of penetration $20 \mu \mathrm{m}$ ). The spectra were acquired as described above.

Identification of the Degradation Products by High Performance Anion Exchange Chromatography with Pulsed Amperometric Detection (HPAEC-PAD). The identification of the degradation products will allow for the understanding of the modes of action of the different enzymes on the starch substrates and will give information about the potential toxicity of the products released, as a result of enzymatic degradation. This analysis was performed using a high
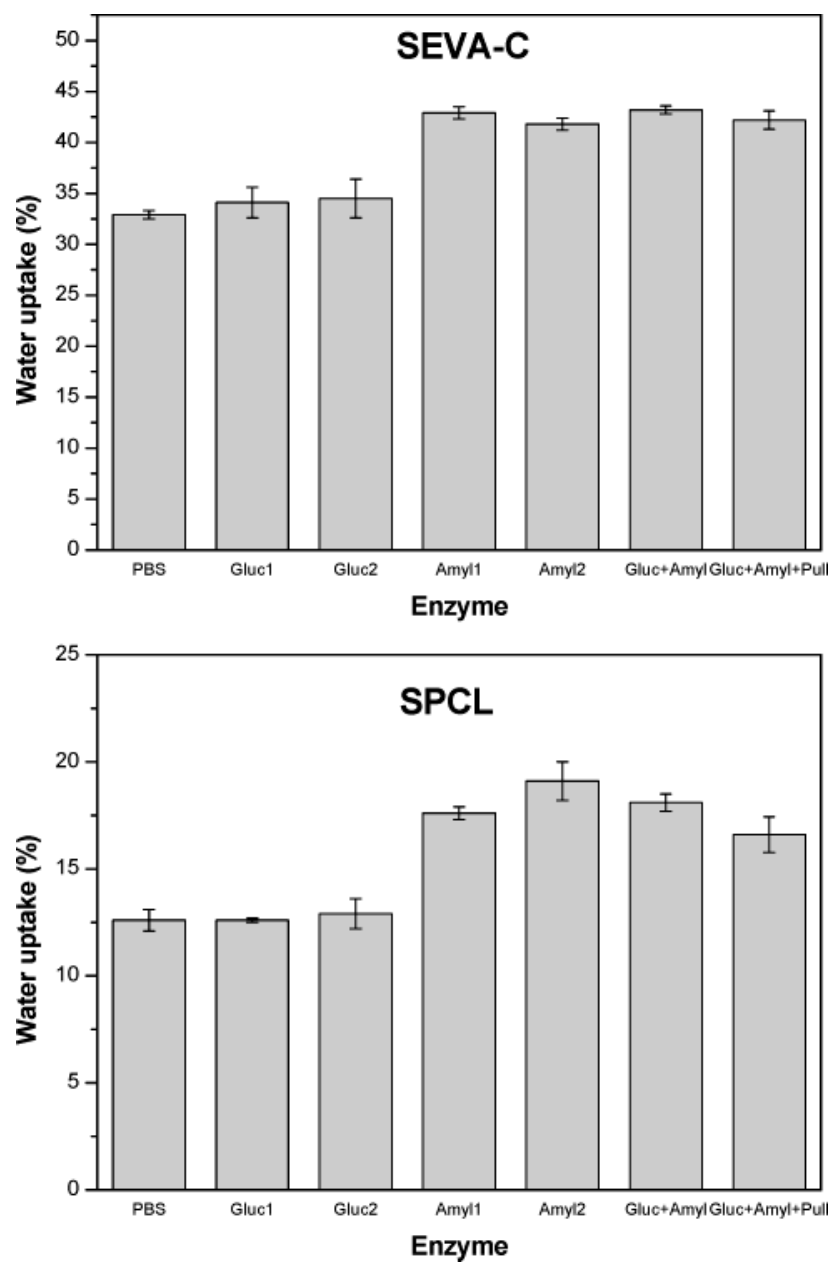

Figure 1. Percentage of water uptake of SEVA-C and SPCL materials after 6 weeks of incubation at $37^{\circ} \mathrm{C}$ in different enzyme solutions. The data points in the figure represent the mean of four replicates and error bars the standard deviation.

performance anion exchange chromatography system DX 300 from Dionex. Diluted samples were injected $(20 \mu \mathrm{L})$ in a CarboPac PA1 column $(4 \times 250 \mathrm{~mm})$ and eluted with a gradient composed of $10 \%$ of $\mathrm{NaOH}(20 \mathrm{mM})$ and $90 \%$ of water at a flow rate of $0.8 \mathrm{~mL} / \mathrm{min}$. Detection was made by a pulsed amperometric detector (Dionex). Glycerol and glucose solutions were also injected in order to determine their retention time and consequently to identify the peaks in the chromatograms of the different samples.

\section{Results and Discussion}

Physical and Chemical Characterization. Water Uptake and Weight Loss. After implantation, biomaterials interact with surrounding fluids by first absorbing water, which initiate their degradation process. The absorption of water may make the material more flexible ${ }^{26}$ and causes dimensional changes. On the other hand, higher water absorption usually accelerates the hydrolysis process. ${ }^{1}$ In Figure 1, the percentage of water uptake for the two starch based materials is plotted, in the various conditions studied, during 6 weeks of incubation. Comparing the two polymeric blends, the percentage of water uptake is lower in the case of SPCL, this behavior being related with the different amounts of starch, as well the crystallinity and hydrophobocity character 

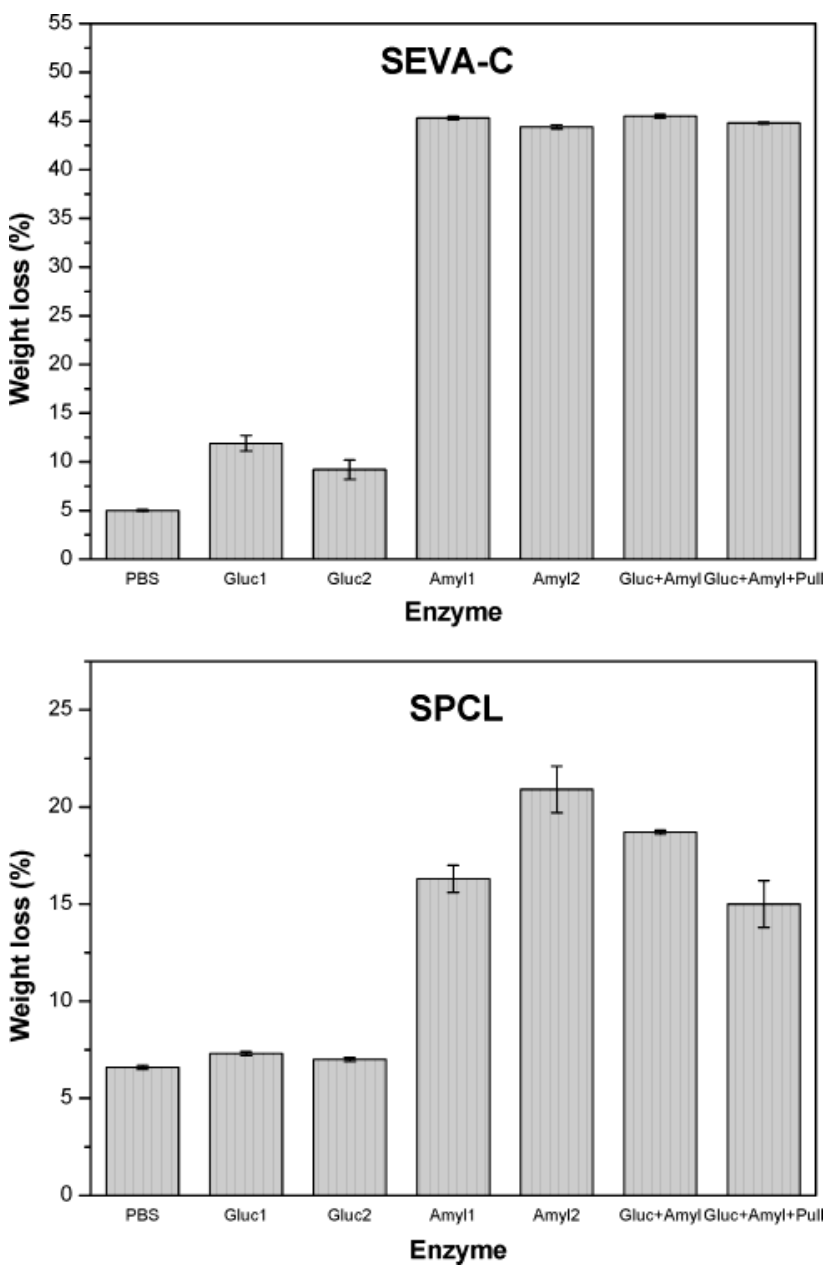

Figure 2. Weight loss of SEVA-C and SPCL materials after 6 weeks of incubation at $37^{\circ} \mathrm{C}$ in different enzyme solutions. The data points in the figure represent the mean of four replicates and error bars the standard deviation.

of the materials. It is known that polycaprolactone (PCL) is a very crystalline polymer that is quite hydrophobic, ${ }^{27}$ which makes the diffusion of water and enzymes more difficult. Nevertheless, it was possible to note that the presence of $\alpha$-amylase in solution leads to higher levels of water absorption. This phenomenon can be related with an increased permeability of the materials caused by the removal of part of the starch phase from the blend as a result of enzymatic hydrolysis (Figure 2). The enzyme concentration did not influence significantly the percentage of water uptake of the materials, and these results are in accordance with weight loss data (Figure 2), because no increased percentage of degradation was observed using higher enzyme concentration.

Figure 2 shows the weight loss for SEVA-C and SPCL materials after the incubation period. As it can be observed, the SEVA-C material shows a weight-loss of $45 \%$ after being incubated with $\alpha$-amylase, which seems to indicate that a great part of the starch present in the blend (50/50, wt \%) has been degraded. When the glucoamylase enzyme was used, about $12 \%$ of weight loss was obtained. These differences are related with the modes of action of the two enzymes on the starch molecule, producing therefore, distinct effects. By combining the two enzymes, no significant increase on weight loss was observed, but the amount of
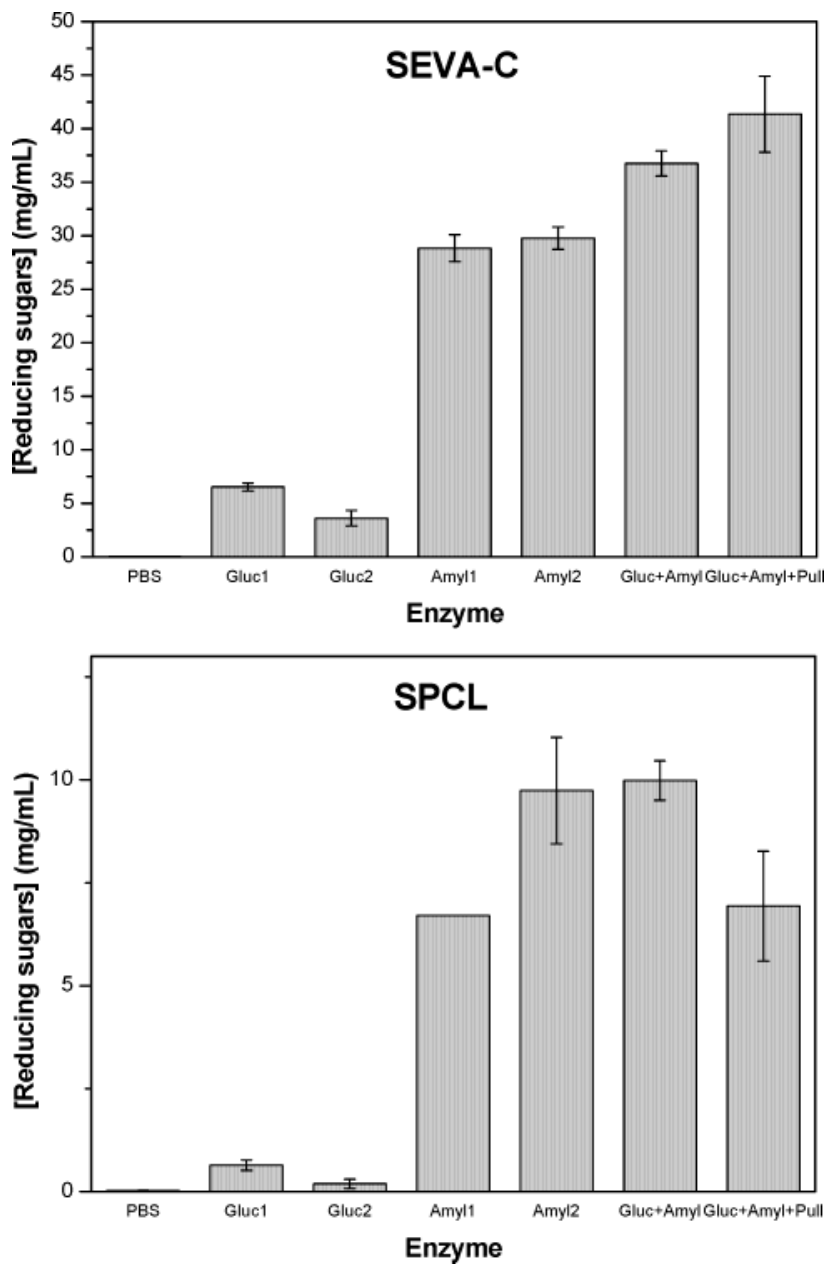

Figure 3. Enzyme activity on SEVA-C and SPCL polymeric blends, measured as the concentration of reducing sugars released into the solution, after incubation of the materials in different enzyme solutions at $37^{\circ} \mathrm{C}$ for 6 weeks. The data points in the figure represent the mean of four replicates and error bars the standard deviation.

reducing sugars found in solution was higher (Figure 3). A weight loss of $5 \%$ was also observed when the samples were incubated in buffer solution, which is related with the leaching of plasticizers and other additives (Figure 10) used during processing and not with polymer chain scission because no reducing sugars were detected in the degradation liquors in this case (Figure 3). These results reveal that the starch component of SEVA-C blend can be fully degraded in a short period of time in the presence of proper $\alpha$-amylase concentrations, although it is known that in SEVA-C starch is complexed with EVOH as forming an intra-penetrating network. $^{20,24,28}$

Figure 2 presents also the weight loss observed for the SPCL samples. It is clear that enzymes contribute, in different percentages, to the material degradation and that the incubation with $\alpha$-amylase leads to a higher weight loss than the one obtained with glucoamylase, as observed for SEVA-C. When these two enzymes were combined, the weight loss of SPCL slightly increased, which may indicate a synergy effect.

Comparing the two materials, SEVA-C exhibited a higher degradability, concerning the ability of enzymes to attack the starch component of the blend, which is related with the 
physicochemical structure of the materials and also with the fact of that the concentration of starch is higher in SEVAC.

Enzyme Activity. Enzymatic hydrolysis of insoluble polymers is known to be affected by the mode of interaction between the enzymes and the polymeric chains and involves typically four steps: ${ }^{29}$ (i) diffusion of the enzyme from the bulk solution to the solid surface, (ii) adsorption of the enzyme on the substrate, resulting in the formation of the enzyme-substrate complex, (iii) catalysis of the hydrolysis reaction, and (iv) diffusion of the soluble degradation products from the solid substrate to the solution. The rate of the global reaction is controlled by the slowest step.

The analysis of the degradation liquors (Figure 3), by means of determining the amount of reducing sugars liberated into the solution, supply additional information about the mode of action of the enzymes toward different substrates.

In the case of SEVA-C, the enzyme concentration did not affect significantly the starch hydrolysis during the incubation period studied, but this can be due to enzyme inhibition by hydrolysis products. In fact, it has been reported that $\alpha$-amylase is strongly inhibited by maltose and maltotriose, ${ }^{30}$ and analysis of degradation liquors (Figure 3 ) reveal high concentration of reducing sugars in solution $(\approx 30 \mathrm{mg} / \mathrm{mL})$. For SPCL, a higher $\alpha$-amylase concentration leads to a higher percentage of hydrolysis. Glucoamylase did not produce a significant amount of reducing sugars, and this is in accordance with the results obtained for weight loss (Figure 2).

Tensile Testing. Polymer degradation is associated also with changes in the mechanical properties. In Figures 4 and 5 are represented the secant modulus at $1 \%$ strain $\left(E_{1 \%}\right)$, the ultimate tensile strength (UTS), and the strain at break $\left(\epsilon_{\mathrm{r}}\right)$ for SEVA-C and SPCL materials, respectively. The incubation of SEVA-C and SPCL materials in PBS solution leads to an increase of modulus, when compared with the untreated sample. In previous studies ${ }^{31}$ this effect was also observed during the first stages of degradation of these systems and is related with the leaching out of processing additives such as plasticizers. Without the plasticizer, the material became stiffer, resulting in an increase in the modulus. Glucoamylase enzyme produces a similar effect to the one observed for the buffer solution. This result is in agreement with weight loss results (Figure 2) because no significant increase on the materials weight-loss was observed, relative to the control, and the main effect on the modulus is again the removal of plasticizer after incubation. The presence of $\alpha$-amylase (Amyl1) on the incubation solution causes, however, a reduction of about $50 \%$ on the modulus for SEVA-C and $17 \%$ for SPCL relative to untreated samples. Although in this case there is also the release of plasticizer to the solution (Figure 10), the weight loss analysis (Figure 2) indicates that a great part of the starch was hydrolyzed by $\alpha$-amylase and the degradation of one component of the blend changes significantly the mechanical properties of the materials. The reduction on the modulus is more significant when comparing the effect of $\alpha$-amylase with the control sample (incubated in PBS solution only), where there is a decrease of $65 \%$ and $58 \%$ for SEVA-C and SPCL, respectively. The later com-
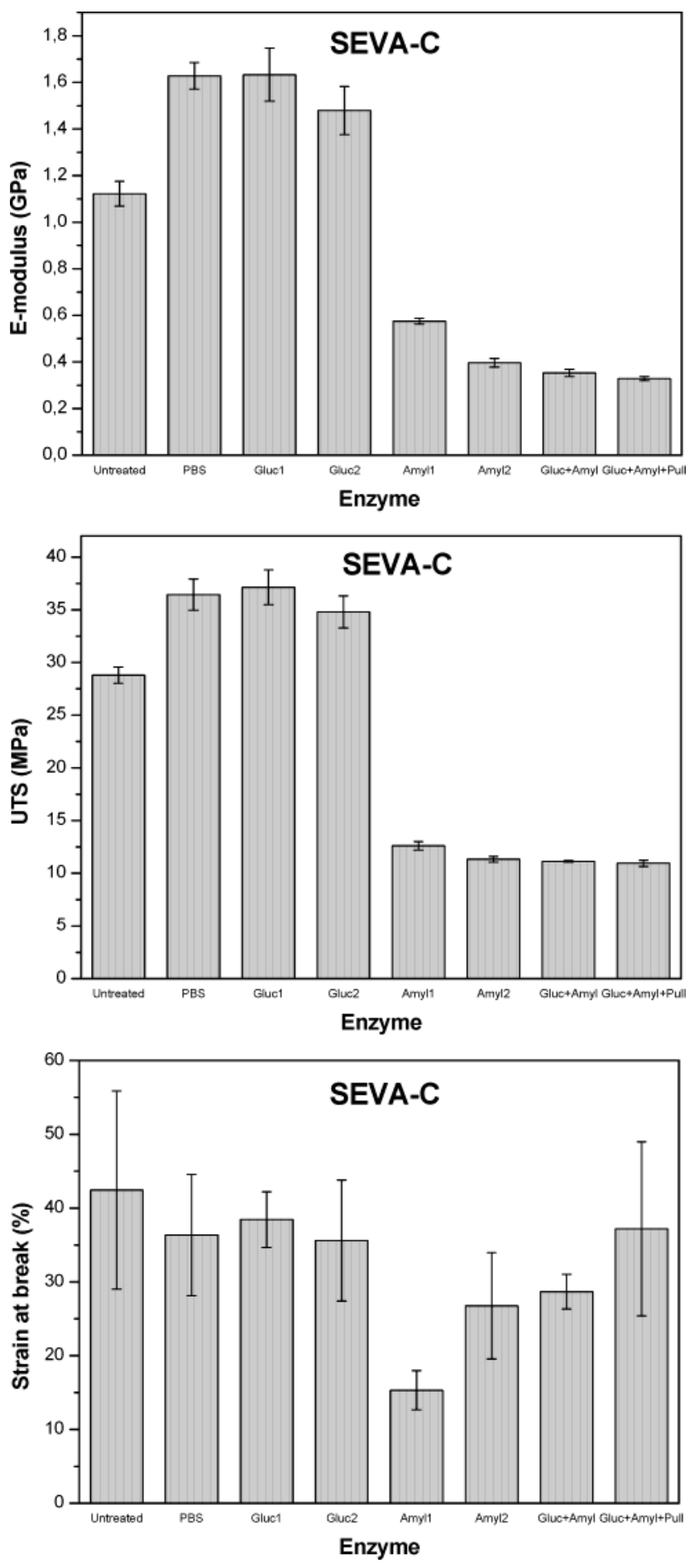

Figure 4. Tensile tests results for SEVA-C material after enzymatic degradation for 6 weeks. The data points in the figure represent the mean of five replicates and error bars the standard deviation.

parison is more adequate to evaluate the effect of enzymes alone on the mechanical properties of the materials.

The UTS results show, as expected, the same trend as the ones observed for the modulus. The loss of ductility can be evaluated by the change in the strain at break. In all conditions, and for both materials, a decrease was observed on the ductility being more notorious this effect for SPCL.

The presence of other starch degrading enzymes (glucoamylase and pullulanase) in solution with $\alpha$-amylase seems to have a synergistic effect on the contribution to the deterioration of the mechanical properties especially for 

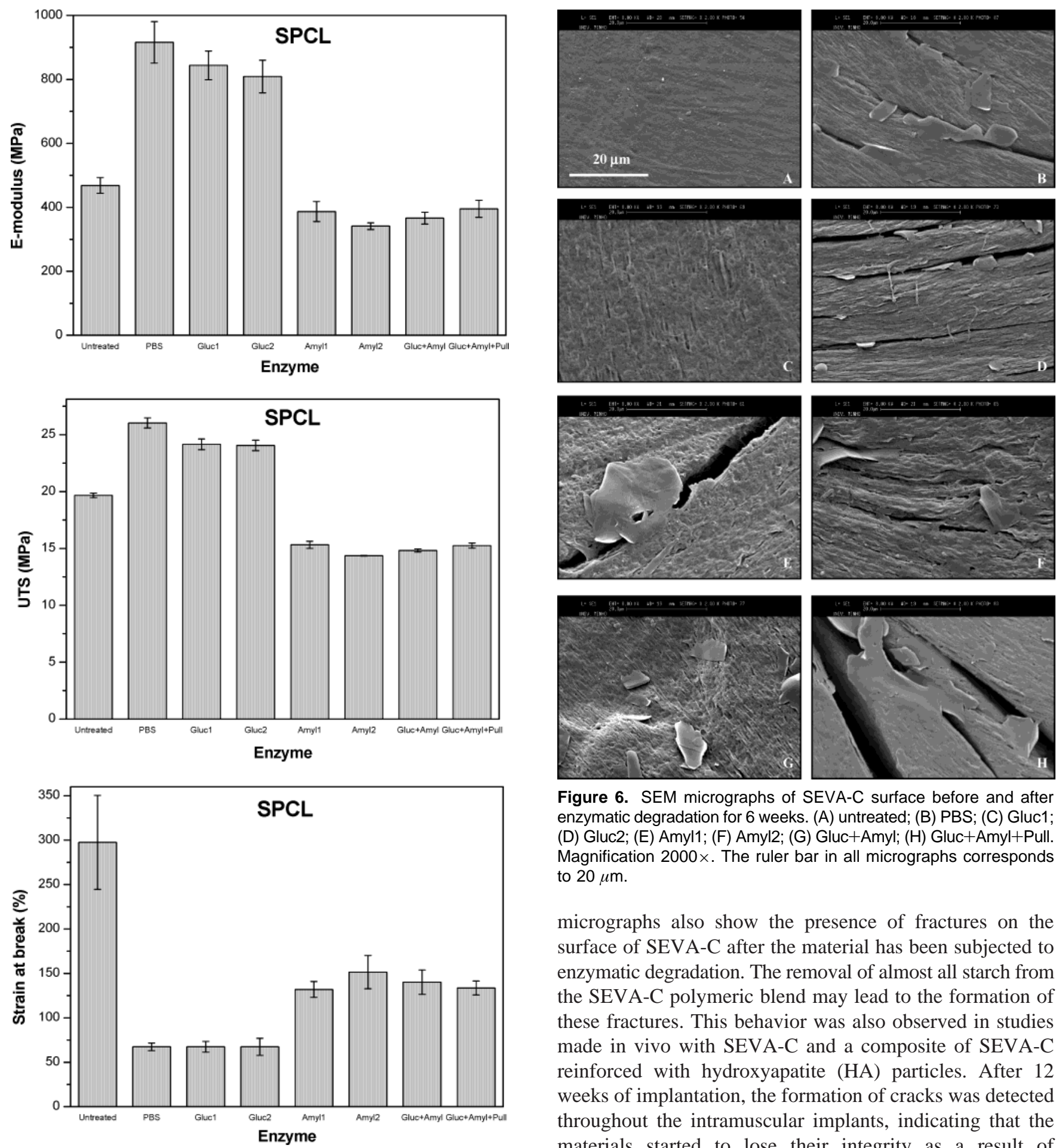

Figure 6. SEM micrographs of SEVA-C surface before and after enzymatic degradation for 6 weeks. (A) untreated; (B) PBS; (C) Gluc1; (D) Gluc2; (E) Amyl1; (F) Amyl2; (G) Gluc+Amyl; (H) Gluc+Amyl+Pull. Magnification $2000 \times$. The ruler bar in all micrographs corresponds to $20 \mu \mathrm{m}$.

micrographs also show the presence of fractures on the surface of SEVA-C after the material has been subjected to enzymatic degradation. The removal of almost all starch from the SEVA-C polymeric blend may lead to the formation of these fractures. This behavior was also observed in studies made in vivo with SEVA-C and a composite of SEVA-C reinforced with hydroxyapatite (HA) particles. After 12 weeks of implantation, the formation of cracks was detected throughout the intramuscular implants, indicating that the materials started to lose their integrity as a result of biodegradation. ${ }^{32}$

Analyzing the SEM micrographs of SPCL samples after degradation for 6 weeks. The data points in the figure represent the mean of five replicates and error bars the standard deviation.

SEVA-C. $\alpha$-Amylase is, however, the enzyme which produces more significant changes on the overall mechanical properties being, therefore, a key enzyme on the degradation of starch-based biomaterials.

Samples Morphology-SEM. Figures 6 and 7 present the surface morphology of SEVA-C and SPCL after enzymatic degradation for 6 weeks. It is possible to observe that, when the samples were incubated with amylolytic enzymes, the material exhibit a rougher surface, which may be due to the chain scission as a result of the enzymatic hydrolysis. SEM enzymatic degradation (Figure 7), it is possible to observe the presence of small pores $(\mathrm{C}, \mathrm{D}, \mathrm{E}, \mathrm{G}$, and $\mathrm{H})$ at the surface, showing the degradation effect of enzymes on the material.

Chemical Changes-FTIR-ATR Spectroscopy. Figure 8A shows the IR spectra for corn starch where the relevant bands are shown, namely at $3450 \mathrm{~cm}^{-1}$ related to the $\mathrm{OH}$ group and at $1150-1040 \mathrm{~cm}^{-1}$ corresponding to $-\mathrm{C}-\mathrm{O}-\mathrm{C}-$ in glycosidic bonds. ${ }^{33}$ Figure $8 \mathrm{~B}$ shows the differences between the spectrum of polycaprolactone (PCL) and the blend of PCL with corn starch (SPCL). The characteristics peaks of PCL are located at $1740 \mathrm{~cm}^{-1}$, corresponding to the $\mathrm{C}=\mathrm{O}$ 

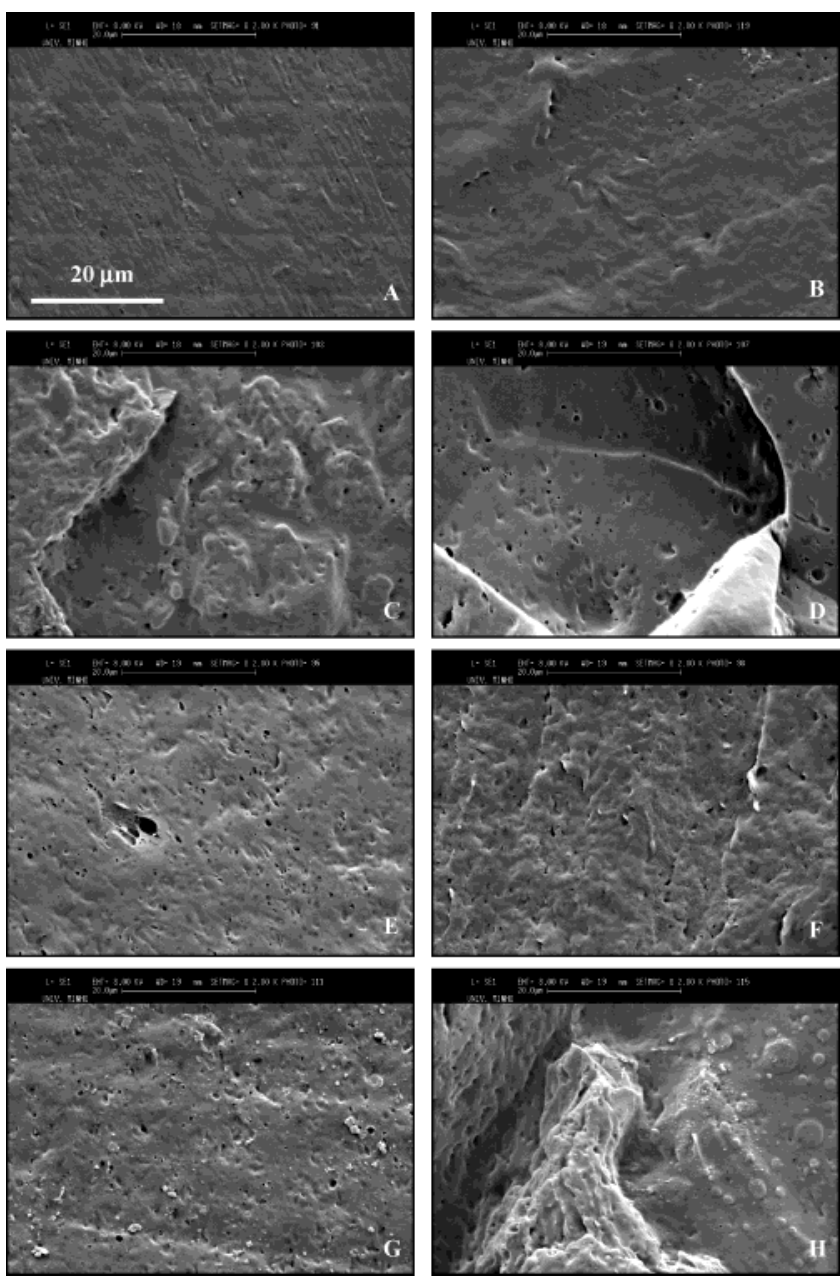

Figure 7. SEM micrographs of SPCL surface before and after enzymatic degradation for 6 weeks. (A) untreated; (B) PBS; (C) Gluc1; (D) Gluc2; (E) Amyl1; (F) Amyl2; (G) Gluc+Amyl; (H) Gluc+Amyl+Pull. Magnification $2000 \times$. The ruler bar in all micrographs corresponds to $20 \mu \mathrm{m}$.

stretch ester carbonyl group. The peaks at 1600-1580 and $1200-1000 \mathrm{~cm}^{-1}$ are related to asymmetric stretch of $-\mathrm{COO}-$ and the stretch of the $-\mathrm{C}-\mathrm{O}$ bond at the main polymer chain. ${ }^{34}$ The SPCL spectrum exhibits the same characteristics peaks of PCL but also peaks from corn starch, namely the peaks related with $\mathrm{OH}$ group and $-\mathrm{C}-\mathrm{O}-\mathrm{C}-$ of glycosidic bonds typically from starch.

The FTIR-ATR spectroscopy technique was used to analyze the changes that occurred in the chemical composition of starch-based polymers after enzymatic degradation. In Figure 9, it is possible to observe that, after degradation with $\alpha$-amylase, the intensity of the peak at $1150-1040 \mathrm{~cm}^{-1}$ decreased, indicating the action of $\alpha$-amylase in cleaving the glycosidic linkages of starch. In the case of SPCL, it is possible to visualize the decrease of intensity in the same peak after enzymatic degradation but also a decrease on the peak of $\mathrm{OH}$ group. When the materials were incubated only in PBS, no significant changes in chemical composition occurred.

Analysis of the Degradation Products-HPAEC-PAD. The development of materials for biomedical applications requires extensive biological testing to demonstrate safety both of the material and its degradation components. ${ }^{5} \mathrm{~A}$ potential disadvantage of using biodegradable polymers in
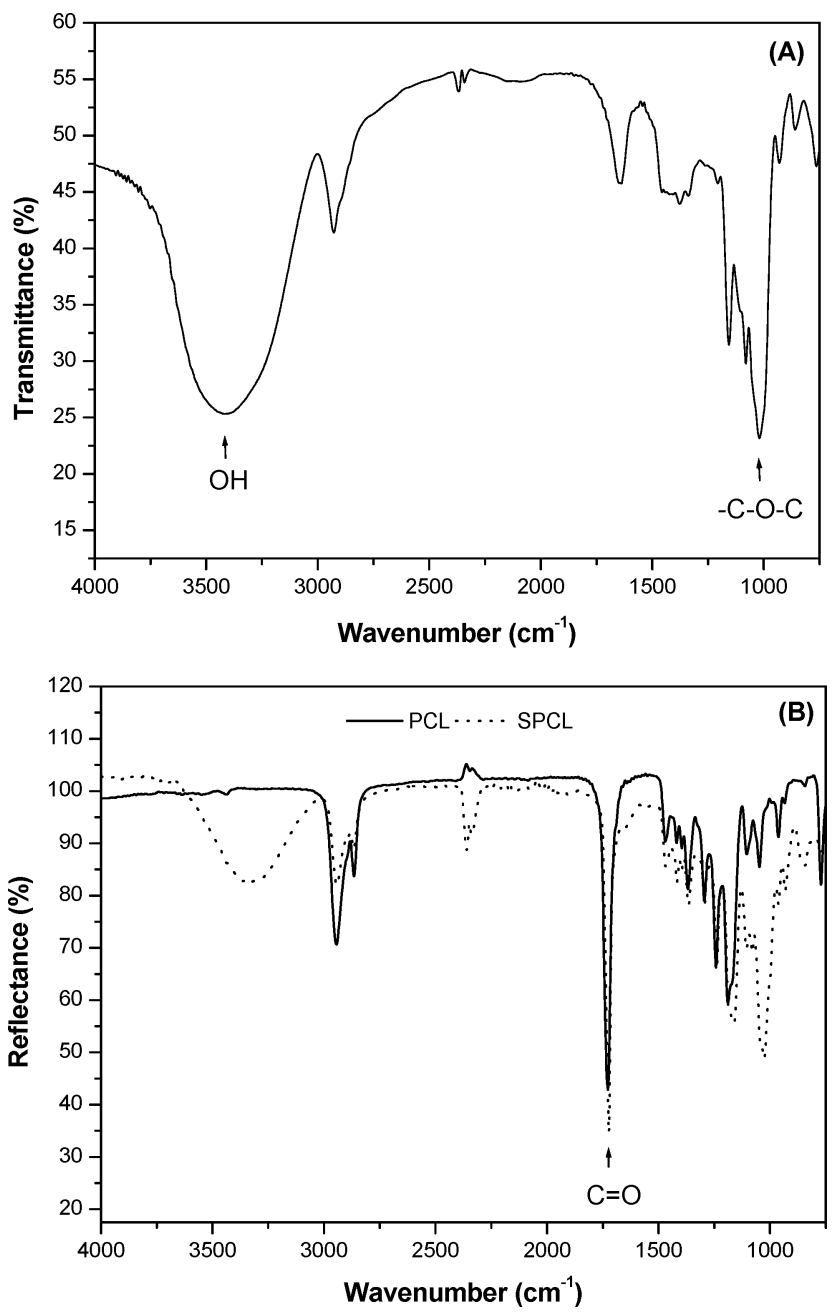

Figure 8. IR spectra of (A) corn starch and (B) polycaprolactone (PCL) and corn starch-polycaprolactone (SPCL) polymeric blend showing the characteristics peaks of each material.

biomedical applications is the eventual toxicity of the degradation products. Biodegradable polysaccharides, like starch, are of interest because their degradation occurs naturally in the human body. ${ }^{22}$ In this work, the products released into the solution after degradation of starch-based polymers with amylolytic enzymes were identified by HPAEC-PAD. Figure 10 shows the chromatogram obtained in the analysis of the degradation liquor of SEVA-C incubated with $\alpha$-amylase. The main products were identified as glycerol (peak 1), glucose (peak 2), and a minor peak (peak 3) related to other oligosaccharides. Although the chromatograms of the other samples are not shown, the presence of glycerol was detected in all of the conditions studied, because it is known that glycerol is used as plasticizer during processing and is normally released after immersion in water. In the case of the control, only the peak corresponding to glycerol appeared on the chromatogram.

Glucose is the main product observed after enzymatic degradation. It should be expected to observe other maltooligosaccharides, because $\alpha$-amylase cleaves the glycosidic linkages of starch in a random manner. These maltooligosaccharides could be converted, however, to glucose by $\alpha$-amylase because these substrates are soluble in solution and, therefore, easily accessible to enzymatic hydrolysis. 

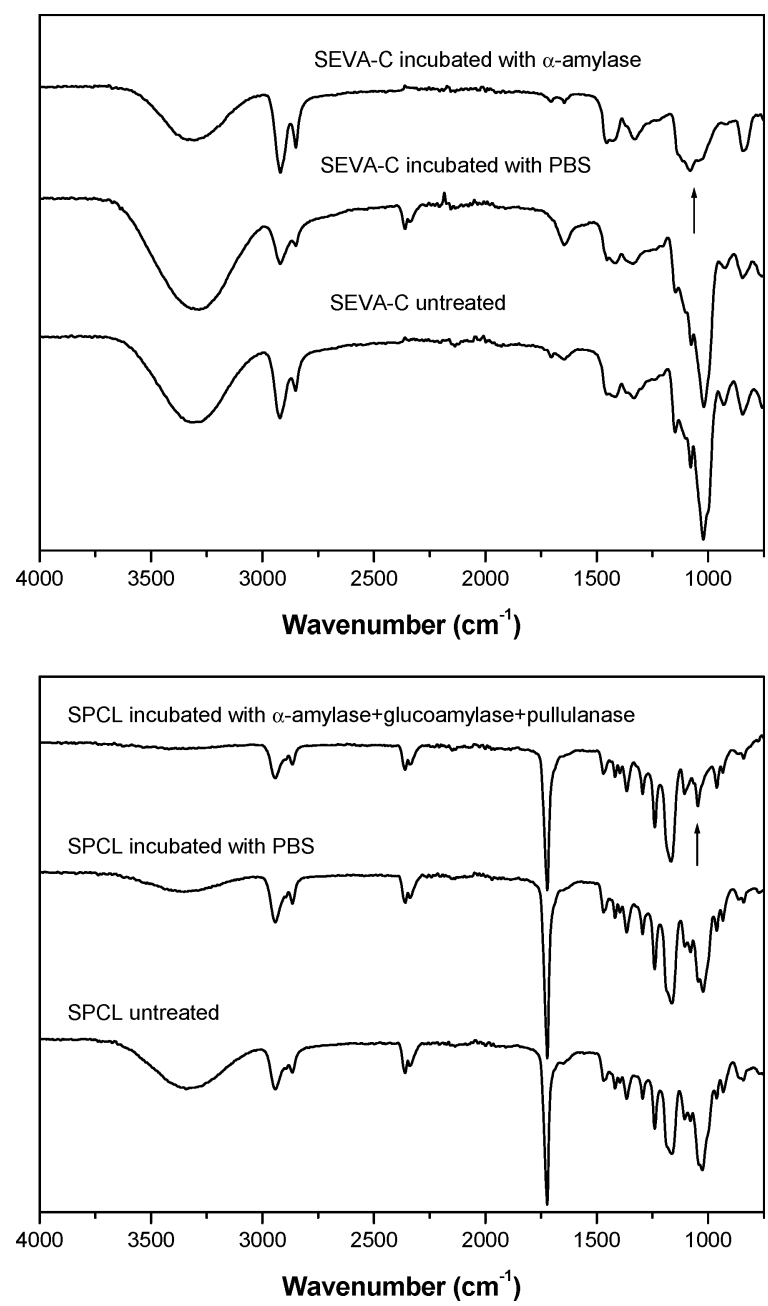

Figure 9. IR spectra of SEVA-C and SPCL materials before and after enzymatic degradation for 6 weeks showing the main changes in the chemical composition.
The same degradation products were identified in the degradation solutions of SPCL samples, and therefore, the corresponding chromatogram is not shown.

This result shows that the enzymatic degradation of starch polymers leads to products that can be integrated in the normal metabolic pathways of living organisms presenting, therefore, low or non toxic effect.

In this study, it was demonstrated that the starch component, present in polymeric blends, could be hydrolyzed by amylolytic enzymes. This result envisages the potential versatility of these materials to be used as carriers for the controlled release of a variety of bioactive agents or in other biomedical applications where it is desired to have biomaterials with controlled degradation. Such a feature can be achieved by incorporating on these materials, using adequate enzyme immobilization methods, an appropriate amount of a specific enzyme. The possibility of controlling the degradation rate of starch-based biomaterials, by incorporating $\alpha$-amylase through biomimetic calcium-phosphate coatings without loss of enzyme activity, was already shown in a previous publication. ${ }^{35}$ Other enzyme immobilization techniques are being investigated in our research group to develop biomaterials with enzymatically controlled degradation rate.

Synthetic polymers, such as EVOH and PCL, can also be degraded by enzymatic oxidation and/or hydrolysis after implantation. It has been reported that polycaprolactonebased biomaterials can be enzymatically degraded by lipase, ${ }^{36}$ cholesterol esterase, ${ }^{37,38}$ and carboxyl esterase, ${ }^{37}$ because these enzymes catalyze the hydrolysis of the ester bonds present in polyesters. These enzymes are present in the human body ${ }^{38}$ and may be involved on the biodegradation of these synthetic polymers. This indicates that the degradation of starch polymeric blends can be modulated by enzymatic means and further work will investigate the effect

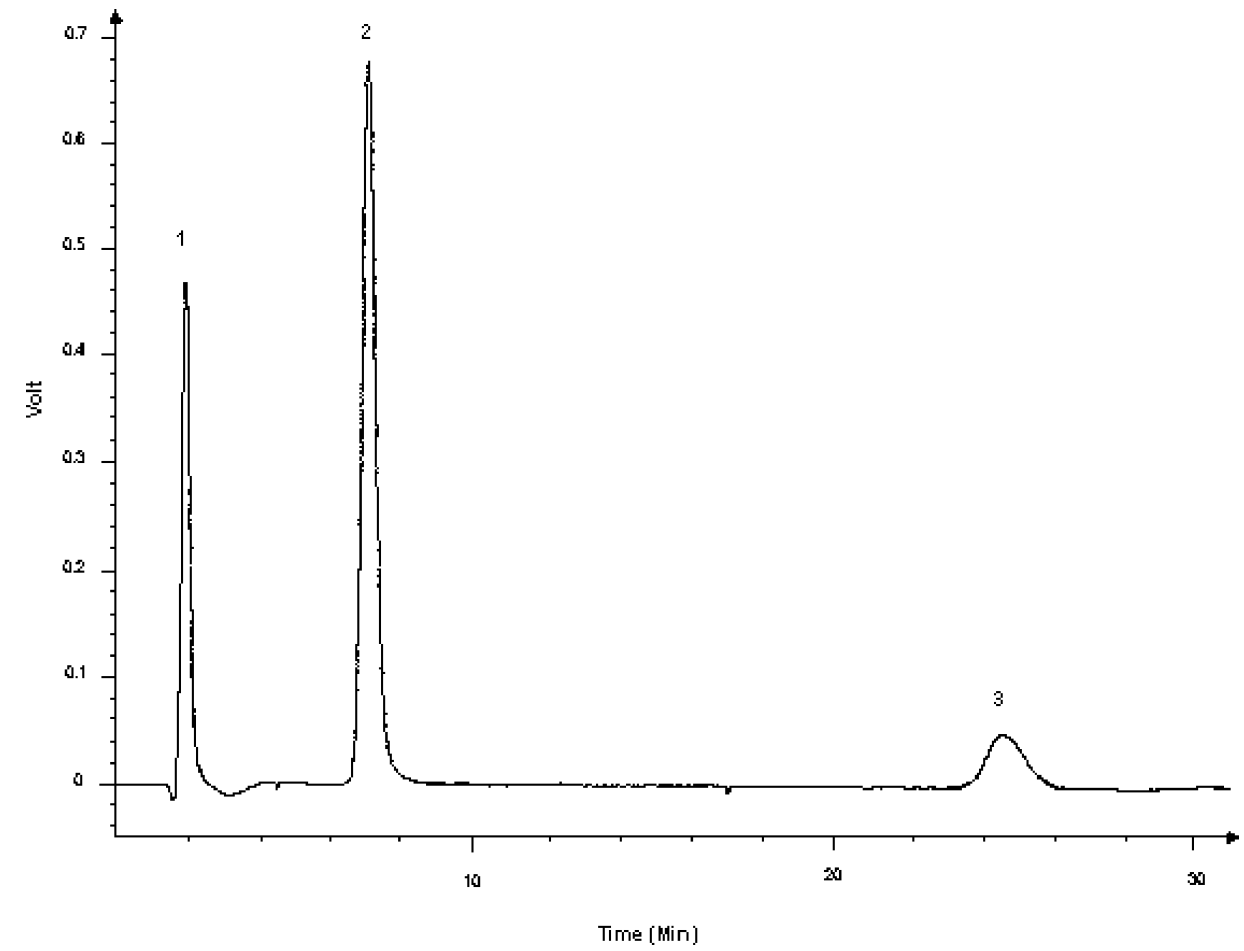

Figure 10. Chromatogram of the degradation solution of SEVA-C incubated with $\alpha$-amylase. Elution conditions were as described in materials in methods. 
of other physiologically important enzymes such as lipase, carboxyl esterase, oxidative systems (alcohol dehydrogenase, peroxidase, xanthine oxidase, catalase $)^{39,40}$ on the degradation behavior of these materials during long-term incubation periods.

\section{Conclusions}

In this work, it was demonstrated that SEVA-C and SPCL polymeric blends are susceptible to enzymatic degradation by amylolytic enzymes (glucoamylase and $\alpha$-amylase), as observed by changes in their physicochemical properties (weight loss and tensile properties) and by the presence of reducing sugars detected in solution after incubation of the materials with the enzymes. FTIR and SEM analysis also confirmed the degradation of the starch blends carried out by the enzymes. In contrast, the incubation of the polymers in buffer only did not cause significant changes on the material's properties and morphology, contributing mainly to the leaching of plasticizers and other processing additives. The percentage of degradation of these materials was shown to be dependent on the modes of action of each enzyme and on its concentration. $\alpha$-Amylase is responsible, as expected, by the highest degradation rate of starch polymeric blends, being, therefore, a key enzyme when studying the enzymatic degradation of starch-based biomaterials. Chemical composition, processing conditions, and structure of the starch polymeric blends also influence the rate of enzymatic hydrolysis by limiting the accessibility of enzymes to the starch substrate influencing, therefore, their degradation profiles. The hydrolysis of starch-based polymers, by amylolytic enzymes, resulted in innocuous degradation products, such as glucose and other maltooligosaccharides.

Acknowledgment. H. S. Azevedo thanks the Portuguese Foundation for Science and Technology for providing her a postdoctoral scholarship (SFRH/BPD/5744/2001). This work was partially supported by FCT Foundation for Science and Technology, through funds from the POCTI and/or FEDER programs.

\section{References and Notes}

(1) Hubbell, J. A. Biomaterials in tissue engineering. Bio/Technol. 1995, $13,565-576$

(2) Peppas, N. A.; Langer, R. New challenges in biomaterials. Science 1994, 263, 1715-1720.

(3) Hubbell, J. A. Bioactive biomaterials. Curr. Opin. Biotechnol. 1999, 10, 123-129.

(4) Langer, R.; Vacanti, J. P. Tissue Engineering. Science 1993, 260, 920-926.

(5) Hubbell, J. A. Synthetic biodegradable polymers for tissue engineering and drug delivery. Curr. Opin. Solid State Mater. Sci. 1998, 3, 246251.

(6) Langer, R. Biomaterials and biomedical engineering. Chem. Eng. Sci. 1995, 50, 4109-4121.

(7) West, J. L.; Hubbell, J. A. Polymeric biomaterials with degradation sites for proteases involved in cell migration. Macromolecules 1999, $32,241-244$

(8) Skarja, G. A.; Woodhouse, K. A. In vitro degradation and erosion of degradable, segmented polyurethanes containing and amino acidbased chain extender. J. Biomater. Sci. Polym. Ed. 2001, 12, 851873

(9) Bruin, P.; Smedinga, J.; Pennings, A. J.; Jonkman, M. F. Biodegradable lysine diisocyanate-based poly(glycolide-co-epsilon-caprolactone)urethane network in artificial skin. Biomaterials 1990, 11, 291295
(10) Reis, R. L.; Cunha, A. M. Characterisation of two biodegradable polymers of potential application within the biomaterials field. $J$. Mater. Sci. Mater. Med. 1995, 6, 786-792.

(11) Reis, R. L.; Cunha, A. M. New degradable load-bearing biomaterials composed of reinforced starch based blends. J. Appl. Med. Polym 2000, 4, 1-5.

(12) Gomes, M. E.; Reis, R. L.; Cunha, A. M.; Blitterswijk, C. A.; Bruijn, J. D. Cytocompatibility and response of osteoblastic-like cells to starch based materials: effects of several additives and processing conditions. Biomaterials 2001, 22, 1911-1917.

(13) Marques, A. P.; Reis, R. L.; Hunt, J. A. The biocompatibilty of novel starch-based polymers and composites: in vitro studies. Biomaterials 2002, 23, 1471-1478.

(14) Pereira, C. S.; Cunha, A. M.; Reis, R. L.; Vázquez, B.; San Román, J. New starch-based thermoplastic hydrogels for use as bone cements or drug delivery carriers. J. Mater. Sci. Mater. Med. 1998, 9, 825833.

(15) Malafaya, P. B.; Elvira, C.; Gallardo, A.; San Román, J.; Reis, R. L. Porous starch-based drug delivery systems processed by a microwave route. J. Biomater. Sci. Polym. Ed. 2001, 12, 1227-1241.

(16) Elvira, C.; Mano, J. F.; San Román, J.; Reis, R. L. Starch based biodegradable hydrogels with potential biomedical applications as drug delivery systems. Biomaterials 2002, 23, 1955-1966.

(17) Espigares, I.; Elvira, C.; Mano, J. F.; Vázquez, B.; San Román, J.; Reis, R. L. New partially degradable and bioactive acrylic bone cements based on starch blends and ceramic fillers. Biomaterials 2002, 23, 1883-1895.

(18) Gomes, M. E.; Ribeiro, A. S.; Malafaya, P. B.; Reis, R. L.; Cunha, A. M. A new approach based on injection moulding to produce biodegradable starch-based polymeric scaffolds: morphology, mechanical and degradation behaviour. Biomaterials 2001, 22, 883889

(19) Gomes, M. E.; Godinho, J. S.; Tchalamov, D.; Cunha, A. M.; Reis, R. L. Alternative tissue engineering scaffolds based on starch: processing methodologies, morphology, degradation, mechanical properties and biological response. Mater. Sci. Eng. C 2002, 20, 1926.

(20) Reis, R. L.; Cunha, A. M. Starch and starch based thermoplastics In Encyclopedia of Materials Science and Technology (11 volumes); Jurgen, K. H., Buschow, R., Cahn, W., Flemings, M. C., Ilschner, B., Kramer, E. J., Mahajan, S., Eds.; Pergamon-Elsevier Science: Amsterdam, 2001; pp 8810-8816, Volume on Biological and Biomimetic Materials.

(21) Nichols, B. L.; Eldering, J.; Avery, S.; Hahn, D.; Quaroni, A.; Sterchi, E. Human small intestinal maltase-glucoamylase cDNA cloning. $J$. Biol. Chem. 1998, 273, 3076-3081.

(22) Dumoulin, Y.; Cartilier, L. H.; Mateescu, M. A. Cross-linked amylose tablets containing $\alpha$-amylase: an enzymatically controlled drug release system. J. Controlled Release 1999, 60, 161-167.

(23) Lorentz, K. Properties of human alpha-amylases from urine, pancreas, and saliva. Enzyme 1982, 28, 233-241.

(24) Bastioli, C. Properties and applications of Mater-Bi starch-based materials. Polym. Degrad. Stability 1998, 59, 263-272.

(25) Ghose, T. K. Measurement of cellulase activities. Pure Appl. Chem. 1987, 59, 257-268.

(26) Hasirci, V.; Lewandrowski, K.; Gresser, J. D.; Wise, D. L.; Trantolo, D. J. Versatility of biodegradable polymers: degradability and in vivo application. J. Biotechnol. 2001, 86, 135-150.

(27) Seretoudi, G.; Bikiaris, D.; Panayiotou, C. Synthesis, characterization and biodegradability of poly(ethylene succinate)/poly( $\epsilon$-caprolactone $)$ block copolymers. Polymer 2002, 43, 5405-5415.

(28) Mano, J. F.; Reis, R. L.; Cunha, A. M. Effects of moisture and degradation time over the mechanical dynamical performance of starch-based biomaterials. J. Appl. Polym. Sci. 2000, 78, 23452357

(29) Rahmouni, M.; Chouinard, F.; Nekka, F.; Lenaerts, V.; Leroux, J. C. Enzymatic degradation of cross-linked high amylose starch tablets and its effect on in vitro release of sodium diclofenac. Eur. J. Pharm. Biopharm. 2001, 51, 191-198.

(30) Leloup, V. M.; Colonna, P.; Ring, S. G. $\alpha$-amylase adsorption on starch crystallites. Biotechnol. Bioeng. 1991, 38, 127-134.

(31) Leonor, I. B.; Sousa, R. A.; Cunha, A. M.; Reis, R. L.; Zhong, Z. P.; Greenspan, D. Novel starch thermoplastic/bioglass composites: mechanical properties, degradation behaviour and in vitro bioactivity. J. Mater. Sci. Mater. Med. 2002, 13, 939-945.

(32) Mendes, S. C.; Reis, R. L.; Bovell, Y. P.; Cunha, A. M.; Blitterswijk, C. A.; Bruijn, J. D. Biocompatibility testing of novel starch-based 
materials with potential application in orthopaedic surgery: a preliminary study. Biomaterials 2001, 22, 2057-2064.

(33) Pawlak, A.; Mucha, M. Thermogravimetric and FTIR studies of chitosan blends. Thermochim. Acta 2003, 396, 153-166.

(34) Walsh, D.; Furuzono, T.; Tanaka, J. Preparation of porous composite materials by in situ polymerization of porous apatite containing $\epsilon$-caprolactone or methacrylate. Biomaterials 2001, 22, 12051212.

(35) Leonor, I. B.; Azevedo, H. S.; Alves, C. M.; Reis, R. L. Effects of the incorporation of proteins and active enzymes on biomimetic calcium-phosphate coatings. In Bioceramics 15, Key Engineering Materials; Ben-Nissan, B., Sher, D., Walsh, W., Eds.; Trans Tech Publications Inc: Zurich, 2003; pp 97-100, Vols. 240-242.

(36) Gan, Z.; Liang, Q.; Zhang, J.; Jing, X. Enzymatic degradation of poly $(\epsilon$-caprolactone $)$ film in phosphate buffer containing lipases. Polym. Degrad. Stability 1997, 56, 209-213.
(37) Labow, R. S.; Meek, E.; Matheson, L. A.; Santerre, J. P. Human macrophage-mediated biodegradation of polyurethanes: assessment of candidate enzyme activities. Biomaterials 2002, 23, 39693975

(38) Wang, G. B.; Labow, R. S.; Santerre, J. P. Biodegradation of a poly(ester)urea-urethane by cholesterol esterase: Isolation and identification of principal biodegradation products. J. Biomed. Mater. Res. 1997, 36, 407-417.

(39) Sam, A.; Doherty, P. J.; Williams, D. F. The mechanism of oxidativedegradation of biomedical polymers by free radicals. J. Appl. Polym. Sci. 1994, 51, 1389-1398.

(40) Labow, R. S.; Meek, E.; Santerre, P. The biodegradation of poly(urethane)s by the esterolytic activity of serine proteases and oxidative enzyme systems. J. Biomater. Sci. Polym. Ed. 1999, 10, 699-713.

BM0300397 